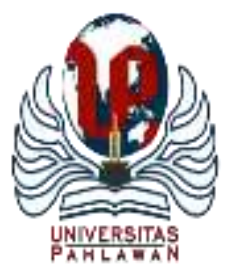

Edukatif : Jurnal Ilmu Pendidikan Volume 4 Nomor 1 Tahun 2022 Halm 602 - 608 EDUKATIF: JURNAL ILMU PENDIDIKAN

Research \& Learning in Education https://edukatif.org/index.php/edukatif/index

\title{
Belajar Pendidikan Dasar pada Sekolah di Jepang
}

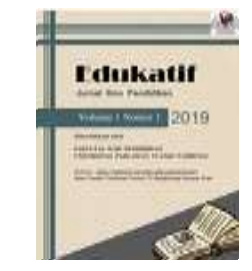

Hani Irawati ${ }^{1 凶}$, Ayu Maulidiyah ${ }^{2}$

Universitas Ahmad Dahlan, Indonesia ${ }^{1,2}$

E-mail : $\underline{\text { hani@pbio.uad.ac.id }}{ }^{1}, \underline{\text { ayu1700008099@webmail.uad.ac.id }}^{2}$

\begin{abstract}
Abstrak
Jepang merupakan salah satu negara yang maju dalam dunia pendidikan. Pendidikan di Jepang menerapkan pendidikan yang modern, akan tetapi tidak meninggalkan nilai luhur dan kebudayaan-kebudayaan dari negara tersebut. Artikel ini ditulis untuk mengetahui seperti apa sistem pendidikan pada sekolah dasar di Jepang. Metode yang digunakan adalah literatur review dengan cara mengumpulkan teori-teori yang relevan, yang sama atau linear dengan topik yang dibahas dari berbagai artikel. Hasil review dari berbagai artikel menunjukkan bahwa kurikulum pendidikan sekolah dasar di Jepang lebih mengedepankan aspek moral dan menerapkan kemandirian kepada siswa dalam belajar dan dalam kehidupan sehari-hari. Kurikulum pendidikan sekolah dasar di Jepang juga dirancang agar siswa memiliki pemahman mitigasi bencana yang baik.
\end{abstract}

Kata Kunci: pendidikan dasar, sekolah, Jepang

Abstract

Japan is one of the most developed countries in the world of education. Education in Japan implements modern education, but does not leave the noble values and cultures of the country. This article was written to find out what the education system looks like in elementary schools in Japan. The method used is review literature by collecting relevant theories, which are the same or linear with the topics discussed from various articles.The results of the review of various articles showed that the curriculum of elementary school education in Japan prioritizes moral aspects and applies independence to students in learning and in everyday life. The curriculum of elementary school education in Japan is also designed so that students have good disaster mitigation.

Keywords: primary education, school, Japanese

Copyright (c) 2022 Hani Irawati, Ayu Maulidiyah

$\checkmark$ Corresponding author

Email : hani@pbio.uad.ac.id

DOI : https://doi.org/10.31004/edukatif.v4i1.1922

ISSN 2656-8063 (Media Cetak)

ISSN 2656-8071 (Media Online) 


\section{PENDAHULUAN}

Setiap negara memiliki sistem pendidikan nasional dan kurikulum nasional yang berbeda yang disesuaikan dengan latar belakang filosofi, kebijakan, dan strategi pendidikan nasional yang secara keseluruhan akan dipengaruhi pula oleh sistem kenegaraan yang dianut dan tujuan yang akan diraih dalam kerangka berbangsa dan bernegara (Wahyudin, 2004). Kurikulum yang dikemabangkan di suatu negara banyak diwarnai oleh berbagai faktor sosial, baik itu faktor ekonomi, politik, sosial budaya, serta aspek kemajuan ilmu pengetahuan dan teknologi.

Jepang merupakan salah satu negara di Asia dengan kualitas pendidikan yang sangat tinggi (Putra, 2017). Jepang diakui sebagai salah satu negara paling maju dengan ekonomi terbesar di dunia. Menariknya, pencapaian ini berkat keberhasilan sistem pendidikan Jepang dalam menghasilkan talenta yang berdaya saing tinggi. Kualitas manusia Jepang yang snagat unggul tidak lepas dari keberhasilan negara tersebut dalam meningkatkan dan menjaga kualitas pendidikan. Keberhasilan penyelenggaraan pendidikan di Jepang dapat dilihat dari nilai Program for International Student Assessment (PISA) Jepang yang selalu berada pada level tinggi secara konsisten, menempati peringkat kedua dalam sains dan kelima dalam matematika pada tahun 2015 dari 72 negara yang berpartisipasi dalam program ini. Sementara Jepang mengalami penurunan pada tahun 2018, berada pada peringkat keenam untuk matematika dan peringkat kelima untuk sains, akan tetapi skor Jepang masih dianggap tinggi.

Best Practice dari sistem pendidikan atau kurikulum negara lain yang relevan dan sesuai dengan kondisi suatu negara bisa diadopsi amupun diadaptasi dan dijadikan dasar pertimbangan untuk perbaikan pendidikan di negara tersebut. Dalam artikel ini, penulis tertarik untuk mempelajari kurikulum pendidikan bahasa Jepang khususnya yang berkaitan dengan pendidikan di tingkat sekolah dasar. Jepang dipilih karena memiliki sistem pendidikan terbaik di dunia dan merupakan salah satu negara maju yang menjadi kiblat atau rujukan negara lain termasuk Indonesia. Yang sangat menarik dari kemajuan pendidikan Jepang dalam dunia pendidikan adalah kemajuan tersebut masih dikelilingi oleh nilai-nilai luhur negara. Cara-cara budaya yang dipraktikkan dalam modernisasi melalui kebijakan sistem pendidikan Jepang memberikan akses bagi masyarakat untuk tetap mantap dalam mengelola nilai-nilai moral dalam kehidupan siswa (Widisuseno, 2019). Orang Jepang sangat bangga dan berpegang teguh pada tradisi dan budaya mereka. Pendidikan dihargai dan dikelola dengan tepat, dan didasarkan pada pengembangan moral dan karakter sebagai bagian integral dari pendidikan. Sistem pendidikan di Jepang umumnya didasarkan pada kombinasi ide-ide Barat dan metode Jepang (Montanesa \& Firman, 2021).

Penelitian-penelitian terdahulu telah banyak yang membahas terkait pendidikan di Jepang mulai dari sekolah dasar sampai pada tingkatan universitas (Puspitarini, 2019), akan tetapi ada artikel ini penulis ingin memaparkan lebih detail pendidikan yang dilakukan pada sekolah dasar di Jepang mulai dari kurikulumnya dan hal-hal yang menarik lainnya yang tidak dimiliki oleh negara lain. Akan dipaparkan juga bagaimana pendidikan karakter dan pendidikan mitigasi bencana dilakukan di sekolah dasar di Jepang.

\section{METODE PENELITIAN}

Artikel ini membahas kurikulum pendidikan sekolah dasar yang diterapkan di Negara Jepang. Jenis penelitian ini adalah literatur review, Metode yang digunakan yaitu narativ review, penelitian diawali dengan mencari artikel-artikel yang berkaitan dengan topik yang akan dibahas yaitu terkait dengan pendidikan anak sekolah dasar di Jepang. Artikel diperoleh dari berbagai jurnal dan juga prosiding seminar, kemudian dilakukan proses validasi. Pertimbangan yang dijadikan sebagai dasar review kualitas literatur yaitu sumber pencarian artikel ilmiah yang terpercaya meliputi: 1). artikel ilmiah dapat diakses secara terbuka; 2). kualitas metodologi penelitian yang digunakan pada artikel ilmiah; 3). kualitas penyajian data dan pembahasan; 4). kecukupan data yang relevan digunakan dalam analisis literatur; dan 5). referensi yang mutakhir. Setelah itu 
data dimasukkan ke dalam tabel dan dilakukan analisis dengan menggunakan analisis data menurtu Miles and Huberman yang terdiri atas reduksi data (data reduction), penyajian data (data display) serta Penarikan kesimpulan dan verifikasi (conclusion drawing/verification) (Lestari \& Irawati, 2020).

\section{HASIL DAN PEMBAHASAN}

\section{Filosofi Pendidikan di Jepang}

Kurikulum pendidikan yang digunakan di suatu negara hampir pasti akan dikaitkan dengan filosofi yang mendasari pendidikan di negara tersebut. Kurikulum merupakan cerminan dari filosofi yang diyakini masyarakat, sehingga penyusunan kuriklum tentunya akan berkaitan dengan tiga bidang filsafat, yaitu ontologi, aksiologi, dan epistemologi (Budiman, 2018). Pendidikan suatu negara tidak dapat dipisahkan dari budaya negara tersebut, budaya Jepang memiliki nilai positif dan negatif. Aspek positif dari pendidikan Jepang adalah semangat ketekunan dan kerja keras, masyarakat Jepang juga dikenal sebagai bangsa dengan disiplin yang ketat dan tingkat produktivitas yang tinggi. Masyarakat Jepang menganut nilai-nilai filosofi kolektivisme, yaitu paham yang memiliki sudut pandang moral, etika politik, ideologi, atau pandangan sosial yang membela kepentingan kolektif atau kelompok. Kolektivisme berfokus pada kepentingan sosial atau nasional dalam berbagai jenis sistem politik, ekonomi, dan pendidikan (Widisuseno, 2019).

Ada sebuah ungkapan yang dipegang teguh oleh orang-orang jepang yaitu Ganbatte Kudasai, sebuah ungkapan yang mengandung banyak arti bagi bangsa Jepang. Ungkapan ini mengandung unsur motivasi dan semangat untuk terus berjuang serta pantang menyerah (Azhari, 2011). Semangat pantang menyerah inilah yang kemudian membangun karakter bangsa Jepang yang tangguh, teliti, rajin dan pantang menyerah. Pada tahun 1945 pada saat Hiroshima dan Nagasaki di bom atom dan porak poranda, ternyata Jepang tidak perlu waktu lama untuk kembali bangkit dan menjadi negara yang maju seperti saat sekarang ini karena semangat dan motivasi yang luar biasa.

Filosofi Gambaru yang melahirkan Ganbatte merupakan perwujudan dari filosofi Bushido yang berkembang pada zaman samurai. Pada masa Shogun Tokugawa, perpaduan Shinto dan Budha melahirkan semangat Bushido yang mengajarkan sikap moral positif seperti keberanian, kehormatan dan harga diri, kesetiaan dan pengendalian diri, kesungguhan, kejujuran, hemat, kemurahan dan kerendahan hati, kesopanan dan keramah tamahan, kerja keras, tidak mementingkan diri sendiri, bertanggung jawab, bersih hati, harus tahu malu, serta mementingkan hubungan moral antara atasan dengan bawahan, ayah dengan anak, suami dengan istri, kakak dengan adik, teman dengan teman. Filosofi Bushido yang tertuang dalam semangat Gambaru inilah yang kemudian mewarnai kehidupan masyarakat Jepang sehari-hari. Hal ini menghasilkan sebuah masyarakat Jepang yang mandiri dan tangguh. Selain pantang menyerah dan kerja keras, semangat Gambaru menghasilkan budaya masyarakat Jepang yang haus akan ilmu pengetahuan.

Karakter negara Jepang dibentuk dengan filosofi bushido zaman samurai, kemudian diperkuat dengan keterbukaan dan modernisasi Jepang melalui Restorasi Meiji. Jepang menjadi negara pertama di Asia yang mengadopsi prinsip demokrasi Barat dengan membentuk parlemen dalam sistem politiknya. Semangat belajar ini kemudian diteruskan pasca Perang Dunia II, ketika masyarakat Jepang belajar keunggulan produk Barat dan kemudian meniru dan mengembangkan inovasinya untuk menciptakan produk yang mampu bersaing dengan produk Barat.

Jepang adalah salah satu negara Asia Timur yang dipengaruhi oleh pemikiran Konfusianisme seperti Cina dan Korea Selatan. Ajaran ini sangat menjunjung tinggi pendidikan dan pengembangan kepribadian yang kuat, serta tidak dapat memisahkan teori dan praktek. Dikatakan juga bahwa leluhur kaisar membangun kerajaan berdasarkan nilai-nilai luhur dan abadi. Filosofi ini terkadang mempengaruhi filosofi pendidikan Jepang (Budiman, 2018). 


\section{Sekolah Dasar di Jepang}

Pendidikan di Jepang terdiri dari sistem 6-3-3-4, SD 6 tahun, SMP 3 tahun, SMA 3 tahun, universitas 4 tahun atau lebih (Mulyadi, 2014). Wajib belajar di Jepang adalah pendidikan sembilan tahun, yang wajib bagi anak usia 6-15 tahun atau SD dan SMP (Mulyadi, 2019). Tidak ada ujian kenaikan kelas pada pendidikan dasar, tetapi siswa yang menyelesaikan studinya di kelas satu secara otomatis akan naik ke kelas dua seterusnya (Putra, 2017). Ujian hanya akan dilakukan pada saat siswa berada di kelas 4 SD.

Pendidikan dasar (SD) di Jepang disebut Shogakkō. Pada tanggal 1 April setiap tahun, sekolah dasar Jepang memulai tahun ajaran baru dan membuka pendaftaran untuk calon siswa sekolah dasar yang biasanya bersamaan dengan musim sakura. Kelas di Jepang akan ditentukan berdasarkan usia anak per April. Sekolah dasar di Jepang merupakan pendidikan wajib bagi anak usia 6-12 tahun. Hal ini tentunya berbeda dengan batasan usia minimal 7 tahun bagi siswa sekolah dasar di beberapa negara (misalnya Indonesia). Pemerintah Jepang memastikan bahwa semua anak berusia 6 hingga 12 tahun di Jepang dapat bersekolah secara gratis. Jika ada orang tua yang tidak mengizinkan anak Anda bersekolah, makan akan mendapatkan sanksi hukum kepada orang tua tersebut. Hampir 97\% sekolah dasar di Jepang adalah sekolah negeri (Ridlwan \& Ansya'ri, 2021). Biaya pendidikan sebagian besar ditanggung oleh negara, seperti biaya masuk, uang sekolah dan bukubuku sekolah dengan perlengkapan sekolah yang lengkap. Orang tua hanya menyediakan fasilitas lain seperti perlengkapan sekolah, makan siang, dan biaya piknik. Pada saat penerimaan siswa baru, orang tua dan siswa wajib menghadiri upacara pembuakaan dengan memakai baju resmi ber jas dan berdasi bagi orang tua siswa.

\section{Kuriklum Sekolah Dasar di Jepang}

Kurikulum Jepang diatur oleh Kementerian Pendidikan, Kebudayaan, Olahraga, Sains dan Teknologi (MEXT). Kurikulum menggunakan prinsip-prinsip Chi-Toku-Tai. Ini hampir sama dengan tiga domain pengetahuan oleh Bloom: kognitif, afektif, dan psikomotorik (Yanuar, 2021). Chi diartikan sebagai pengetahuan akademik, Toku diartikan sebagai aspek pengembangan nilai, emosi dan karakter siswa, Tai artinya sama dengan tubuh yang sehat. Pemerintah pusat memainkan peran penting dalam mendefinisikan kurikulum nasional, tetapi beberapa kebebasan tetap ada di masing-masing sekolah. Sekolah dasar di Jepang harus memiliki fasilitas olahraga luar ruangan, ruang stadion dalam ruangan, kolam renang, ruang musik, ruang memasak, ruang menggambar, laboratorium komputer, dan perpustakaan yang sama (Puspitarini, 2019)

Sekolah dasar dipimpin oleh kepala sekolah, yang menguasai semua mata pelajaran yang diajarkan kepada siswa. Sekolah dasar Jepang dibagi menjadi kelas bawah (kelas 1-3) dan kelas atas (kelas 4-6). Di kelas bawah, fokusnya adalah pada mata pelajaran bahasa dasar, aritmatika, musik, seni, kerajinan, pendidikan moral, pendidikan jasmani, dan bahasa Jepang (Sunarni, 2017). Siswa kelas 1 sampai kelas 2 hanya belajar perkalian, pembagian, penambahan, dan pengurangan yang dilakukan terus menerus smapai paham. Pendidikan di Jepang selalu memelihara kebudayaan yang dimilki salah satunya terkait dengan bahasa jepang tulisan kanji. Pelajaran bahasa Jepang diajarkan mulai dari kelas satu begitu juga dengan tulisan kanji. Pada saat siswa berada di kelas 1 siswa wajib hafal dan dapat menulis 80 huruf kanji. Pada saat kelas 2 siswa harus bisa menulis 150 huruf kanji. Seikatsuka (kebiasaan hidup) yang diajarkan di kelas 1 dan 2. Mata pelajaran ini bertujuan untuk membiasakan anak-anak dengan cara hidup mandiri sehari-hari. Jepang lebih memilih memperkenalkan tata cara kehidupan sehari-hari kepada anak-anak yang baru menyelesaikan pembelajaran di TK yang lebih memfokuskan kegiatan bermain dari pada belajar di dalam kelas (Putra, 2017).

Pelajaran Ilmu Pengetahuan Alam (IPA) diajarkan sejak kelas tiga, tetapi tidak ada pelajaran Ilmu Pengetahuan Sosial (IPS). Ada mata pelajaran yang disebut life skill yang mengajarkan kemandirian. Siswa yang berada di kelas tiga atau lebih, belajar tentang masalah sosial melalui kursus terpadu. Kegiatan kursus terpadu dapat berupa kesempatan belajar bersama di toko roti, rumah siswa, petani di sekitar sekolah, atau di lingkungan alam seperti pegunungan, sungai dan sumber air. Belajar bahasa Jepang sangat penting sehingga kelas bawah dari kelas 1 sampai 3 akan memakan waktu lebih lama untuk belajar daripada kelas atas dari kelas 4 sampai 6. Belajar bahasa Inggris diajarkan di kelas 5 dan 6 (Riyana, 2008). 


\section{Penanaman Pendidikan Karakter}

Pendidikan pada sekolah dasar di Jepang bertujuan untuk menanamkan nilai kemandirian dan estetika, selain itu juga menitikberatkan pada pendidikan moral dan kepribadian yang dipraktikkan dalam kehidupan sehari-hari, bukan hanya teoritis pada mata pelajaran (Mulyadi, 2019). Siswa SD di Jepang masuk jam delapan pagi dan pulang jam tiga sore. Pada saat berangkat sekolah, lebih banyak siswa yang berjalan kaki atau menggunakan sepeda sebagai alat transportasi, atau dengan menggunakan angkutan umum seperti bus sekolah. Siswa tidak dibiasakan untuk diantar-jemput oleh orang tuanya, akan tetapi siswa berangkat sekolah dengan bersama-sama dengan teman-temannya. Sekolah di Jepang hampir sama di setiap wilayah, baik dari segi bangunan maupun saran dan prasarana yang dimiliki, sehingga tidak ada sekolah favorit (Leni, 2019). Siswa-siswa akan cenderung memilih sekolah yang paling dekat dengan tempat tinggalnya masing-masing. Siswa di jepang biasanya akan menggunakan tas yang sama yang disebut dengan randoseru karena sudah disediakan dari sekolah. Tas ini berbentuk kotak, siswa putra akan menggunakan tas yang berwarna biru dan hitam sedangkan siswa putri akan menggunakan tas yang berwarna-warni. Tas ini akan digunakan selama 6tahun, siswa di Jepang dilarang untuk berganti-ganti tas (Wahyudin, 2004).

Kegiatan pembelajaran dimulai dengan membaca pagi dan belajar pagi sebelum masuk kelas untuk mengikuti pembelajaran (Montanesa \& Firman, 2021). Pendidikan kemandirian dan disiplin diterapkan melalui kegiatan sehari-hari, bukan dalam bentuk teori tetapi praktik secara langsung. Siswa berangkat sekolah sendiri tidak didampingi orang tua, membersihkan kelas dan sekolah, tidak menggunakan jasa kebersihan. Setiap hari siswa sekolah dasar di Jepang akan melaksankan makan siang secara bersama-sama yang disediakan oleh sekolah. Pada kegiatan makan siang untuk menanamkan sikap mandiri pada siswa secara bergiliran siswa-siswa akan melayani teman-temannya mengambil hidangan makan siang dengan menggunakan baju koki, dan setelah kegiatan makan siang ada siswa yang bertugas untuk mencuci peralatan makan dan ada yang membersihkan tempat makan dengan menyapu dan mengepel ruangan (Sam Bamkin, 2020).

Pembelajaran di Jepang lebih banyak pada praktik dari pada teoritis, di sekolah disediakan lapangan terbuka untuk pelajaran olah raga, disediakan berbagai peralatan musik juga pelajaran seni. Setiap akhir tahun akan diadakan pentas seni yang memberikan ruang kepada siswa untuk menunjukkan apa yang telah mereka pelajari dalam satu tahun dalam pelajaran seni. Dalam kegiatan pentas seni ini sekolah akan mengundang orang tua siswa. Kegiatan pentas seni meruapkan salah satu kegiatan yang paling ditunggu-tunggu oleh siswa di Jepang. Pada saat libur musim panas yang berlangsung kurang lebih 45 hari siswa akan mendapatkan tugas untuk membuat sebuah proyek. Proyek tersebut biasanya sudah ada di dalam sebuah buku yang dikenal dengan "buku proyek", tugas yang dibuat biasanya secara individu dan nantinya harus dikumpulkan karena menjadi salah satu penilaian (Shobahiya, 2008).

\section{Pendidikan Mitigasi bencana}

Jepang sebagai salah satu negara di dunia yang paling sering mengalami gempa bumi dan juga tsunami telah memasukkan materi terkait mitigasi bencana ke dalam kurikulum di sekolah dasar (Widiandari, 2021). Hal ini dilakukan agar tercipta masyarakat yang sadar bencana melalui pendidikan menghadapi bencana yang diberikan kepada anak-anak sejak usia dini. Bukan hanya dididik secara fisik dalam evakuasi diri saat bencana, tetapi juga dididik secara mental dan dilatih secara rutin (Adri et al., 2020). Di Jepang, siswa sering dilatih untuk memprediksi bencana alam, seperti gempa bumi dan tsunami. Salah satu materi pelatihan yang diajarkan di tingkat SD adalah cara membaca peta dan mendapatkan petunjuk arah menuju lokasi evakuasi. Mereka diajari, jika terjadi gempa bumi, apa yang harus dilakukan untuk melindungi diri mereka sendiri baik di sekolah, di kamar kecil, di taman, atau di tempat lain. Selain itu, siswa SD juga diajarkan kemana harus mengungsi jika, pada saat gempa, mereka berpisah dari orang tua mereka. Materi pelatihan terkait bencana dinilai mampu mendukung upaya evakuasi yang seringkali berlangsung cepat dalam situasi darurat. Sekolah 
adalah tempat pelatihan yang sangat berguna untuk prediksi bencana. Saat terjadi bencana, risiko kepanikan sangat tinggi, sehingga memberikan pelatihan khusus kepada anak-anak sangatlah penting.

Kuriklum yang didesain sudah memasukkan unsur mitigasi bencana secara utuh (Savitri et al., 2021). Dalam isi pembelajaran kelas 3 dan kelas 4 disipkan mitigasi bencana terkait dengan kebakaran, badai dan banjir, dan gempa bumi, tanah longsor, semburan lumpur, tsunami, atau gunung berapi. Di kelas 5 juga, materi diambil tentang api, badai dan banjir, dan gempa bumi untuk mengajarkan pencegahan bencana. tanggung jawab masyarakat untuk meningkatkan kesadaran tentang pencegahan bencana. Di kelas 6, siswa diajarkan tentang pemulihan pasca bencana dan melakukan operasi penyelamatan secara sistematis dalam keadaan darurat, atau perencanaan konstruksi untuk pemulihan bencana (Ohnishi, 2013).

\section{KESIMPULAN}

Kurikulum Sekolah Dasar di Jepang meliputi pengenalan lingkungan hidup, musik, menggambar, olahraga, kerajinan tangan, pelajaran-pelajaran topik, ilmu-ilmu sains, aritmatik, homemaking, dan sosial. Pada kelas rendah yakni kelas 1 hingga kelas 3 mempunyai jumlah jam belajar lebih banyak jika dibandingkan dengan kelas atas yakni kelas 4 sampai kelas 6. Pendidikan moral sangat kental dalam kegiatan pembelajaran di Jepang baik di dalam kelas maupun di luar kelas. Kurikulum juga dirancang agar siswa sekolah dasar di Jepang memiliki kemampuan mitigasi bencana yang baik.

\section{DAFTAR PUSTAKA}

Adri, K., Rahmat, H. K., Ramadhani, R. M., Najib, A., \& Priambodo, A. (2020). Analisis Penanggulangan Bencana Alam Dan Netech Guna Membangun Ketangguhan Bencana Dan Measyarakat Berkelanjutan Di Jepang. Nusantara: Jurnal Ilmu Pengetahuan Sosial, 7(2), 408-420.

Budiman, M. (N.D.). Mencermati Sistem Pendidikan Di Jepang Sebuah Telaah Studi Perbandingan. Retrieved December 23, 2021, From Http://Unimus.Ac.Id/

Budiman, M. (2018). Mencermati Sistem Pendidikan Di Jepang Sebuah Telaah Studi Perbandingan. Jurnal Penelitian Pendidikan, 1-12. Https://Www.Academia.Edu/6205597/Mencermati_Sistem_Pendidikan_Di_Jepang_Sebuah_Telaah_Stu di_Perbandingan

Leni, N. (2019). Faktor Yang Membuat 7 Negara (Finlandia, Korea Selatan, Hongkong, Jepang, Singapura , Belanda, Kanada) Diakui Memiliki Sistem Pendidikan Terbaik Di Dunia Dalam Kajian Antropologi Dan Matematika. Prosiding Seminar Nasional Matematika Dan Pendidikan Matematika, 219-229.

Lestari, D. G., \& Irawati, H. (2020). Literature Review : Peningkatan Hasil Belajar Kognitif Dan Motivasi Siswa Pada Materi Biologi Melalui Model Pembelajaran Guided Inquiry. Bioma, 2(2), 51-59.

Montanesa, D., \& Firman, F. (2021). Perbandingan Sistem Pendidikan Indonesia Dan Jepang. Edukatif: Jurnal Ilmu Pendidikan, 3(1), 174-179. Https://Doi.Org/10.31004/Edukatif.V3i1.246

Mulyadi, B. (2019). Model Pendidikan Karakter Anak Usia Dini Dan Anak Usia Sekolah Dasar Di Jepang. Kiryoku, 3(3), 141. Https://Doi.Org/10.14710/Kiryoku.V3i3.141-149

Ohnishi, K. (2013). Geography Education Challenges Regarding Disaster Mitigation In Japan. Review Of International Geographical Education Online (Rigeo), 3(3), 230-240.

Puspitarini, D. (2019). Pendidikan Dasar Di Indonesia, Jepang, Dan Amerika Serikat. Prosiding Seminar Nasional Pagelaran Pendidikan Dasar Nasional (Ppdn) 2019, 1(1), 346-361. Http://Www.Seminar.Uad.Ac.Id/Index.Php/Ppdn/Article/View/1449

Putra, A. (2017). Mengkaji Dan Membandingkan Kurikulum 7 Negara (Malaysia, Singapura, Cina, Korea, Jepang, Amerika Dan Finlandia). Https://Doi.Org/10.31227/Osf.Io/Vdz32 
608 Belajar Pendidikan Dasar pada Sekolah di Jepang - Hani Irawati, Ayu Maulidiyah

DOI: https://doi.org/10.31004/edukatif.v4i1.1922

Ridlwan, M., \& Ansya'ri. (2021). Kebijakan Pendidikan Sekolah Dasar 3 Negara (Singapur, Jepang, Korea Selatan) Dan Implikasinya Terhadap Pendidikan Sekolah Dasar Indonesia. Pedagogi: Jurnal Anak Usia Dini Dan Pendidikan Andak Usia Dini, 7(2), 141-149.

Riyana, C. (2008). Studi Perbandingan Kurikulum : Cina , Korea Dan Jepang. 1-28.

Sam Bamkin. (2020). Transition In The Japanese Curriculum How Is The Curriculum Of Elementary And Secondary Schools In Japan Determined.Docx - Google Docs. Https://Docs.Google.Com/Document/D/1 kdwfawxoexkpkbgfymhsz_Obcdrpuxgj/Edit\#Heading=H.Gjdg Xs

Shobahiya, M. (2008). Sistem Pendidikan ( Studi Komparasi Antara Indonesia Dan Jepang ). Ishraqi, Iv(1), 73-91.

Sunarni, N. (2017). Komparasi Kearifan Lokal Sunda Dan Jepang: Pembentuk Karakter Anak. Jentera: Jurnal Kajian Sastra, 6(1), 83. Https://Doi.Org/10.26499/Jentera.V6i1.327

Tujuan, U., Berkelanjutan, P., Indonesia, D. I., Savitri, A. R., Julius, A. M., Sandi, A. W., Ali, F., Widyaningrum, N., Sakti, S. K., Kerta, I. D. K., Nasional, F. K., \& Pertahanan, U. (2021). Nusantara: Jurnal Ilmu Pengetahuan Sosial. 8(1), 142-157.

Wahyudin, D. (2004). Analisis Kurikulum: Studi Komparatif Pengembangan Kurikulum Di Jepang Dan Indonesia. Inovasi Kurikulum, 1, 1-15.

Widiandari, A. (2021). Penanaman Edukasi Mitigasi Bencana Pada Masyarakat Jepang. Kiryoku: Jurnal Studi Kejepangan, 5(1), 26-32. Http://Ejournal.Undip.Ac.Id/Index.Php/Kiryoku\%0apenanaman

Widisuseno, I. (2019). Pola Budaya Pembentukan Karakter Dalam Sistem Pendidikan Di Jepang. Kiryoku, 2(4), 48. Https://Doi.Org/10.14710/Kiryoku.V2i4.48-57

Yanuar, R. F. (2021). Indonesia Dan Jepang. Judha_Pgsd: Jurnal Dharma Pgsd, 1(2), 146-161. 